\title{
EVALUATION OF THE DECISION-MAKING MODE DURING DIGESTIVE ONCOLOGY MULTIDISCIPLINARY MEETINGS: A PROSPECTIVE STUDY IN A MOROCCAN CENTER
}

\author{
Chaimae Charoui ${ }^{1}$, Amine Souadka ${ }^{1,2}$, Saber Boutayeb ${ }^{2,3}$, Rachida Latib ${ }^{4}$, Laila Rifai ${ }^{5}$, Laila Amrani ${ }^{1,2}$, \\ Amine Benkabbou ${ }^{1,2}$, Raouf Mohsine ${ }^{1,2}$, Mohammed Anass Majbar 1,2 \\ ${ }^{1}$ Department of digestive surgical Oncology. National Institute of Oncology, Rabat. Morocco \\ ${ }^{2}$ Research Team in Translational Oncology, Faculty of Medicine and Pharmacy, Mohammed V ${ }^{\text {th }}$ University Rabat, Morocco. \\ ${ }^{3}$ Medical Oncology department. National Institute of Oncology, Rabat. Morocco \\ ${ }^{4}$ Radiology department, National Institute of Oncology, Rabat. Morocco. \\ ${ }^{5}$ Oncogenetics, National Institute of Oncology, Rabat. Morocco.
}

\section{ABSTRACT}

Introduction: The multidisciplinary team oncology meeting (MDT) has become a standard in oncology. The objective of this study was to evaluate the value of a validated tool, the Metric for the Observation of DecisionMaking, in the evaluation of the decision-making mode during the digestive cancer MDT in order to reach recommendations for improvement.

Results: Eight consecutive MDTs were observed ( $\mathrm{N}=228$ patients). On average, 32 patients were discussed by MDT with an average of 2 min $55 \mathrm{~s}$ (interval: $30 \mathrm{~s}-10 \mathrm{~min} 16 \mathrm{~s}$ ) per patient. A decision was reached in $84.6 \%$ of the cases. Although the medical information was judged to be of good quality, the psychosocial information (average 1.29) and the patients' point of view (average 1.03) were judged to be of low quality. For teamwork, the contribution of surgeons (average 4.56) and oncologists (average 3.99) was greater than radiologists (3.12), radiotherapists (1.74) and pathologists (1.02).

Conclusions: The tool made it possible to identify a disparity in the quality of the different aspects of the information and in the participation of specialists, making it possible to identify specific improvement measures. Its regular use would improve the quality of patient care.

Keywords: Decision making, Quality improvement, Multidisciplinary meeting, MDT-MODe, Morocco.

\section{Corresponding Author:}

Mohammed Anass Majbar, MD.

Address: Department of digestive surgical oncology. National Institute of Oncology, Rabat. Morocco.

E-mail: anass.majbar@um5s.net.ma

Tel.: +212668846573

Copyright (C 2012- 2020 Dr. MA. Majbar and al. This is an open access article published under Creative Commons Attribution -Non Commercial - No Derives 4.0 International Public License (CC BY-NC-ND). This license allows others to download the articles and share them with others as long as they credit you, but they can't change them in any way or use them commercially.

doi: $10.46327 /$ msrjg. $1.000000000000 \times 169$

*****Available online in June 30, 2020.

doi url: https://doi.org/10.46327/msrjg.1.000000000000169

\section{BACKGROUND}

The cancer care pathway is complex and involves several stakeholders, in order to allow a precise diagnosis and an optimal and personalized treatment for each case. In this context, multidisciplinary team meetings (MDT) have become the cornerstone of the coordination of the care pathway for cancer patients. MDT has been defined as "a group of people from different health disciplines who come together at any given time (whether physically in one place or by video or teleconference) to discuss a given patient, and who are each able to independently contribute to decisions about diagnosis and treatment for the patient [1]. The described benefits of MDTs are to provide the patient with costeffective, coordinated, consistent care by experts, improve communication between different disciplines, facilitate decision-making, ensure compliance with decisions and offer a training space for young practitioners [2-4]. For these reasons, MDT has become mandatory in several countries and a dominant decision-making model in cancerology worldwide [5].

It has been observed that multidisciplinary and coherent teamwork during MDTs are associated with their effective functioning $[6,7]$. The quality of teamwork in MDTs depends on the relational and 
behavioral skills of the participants, including a climate of respect between team members, good communication, inclusive discussion and the availability of reliable and complete information [811]. Although several tools were created to assess teamwork during MDTs [2, 12, 13], few studies have assessed the quality of MDTs and how to improve in time.

The objective of this study was to evaluate the value of a validated tool, the Metric for the Observation of Decision-Making, in the evaluation of the decisionmaking mode during the digestive cancer MDTs and its ability to identify specific measures for improvement.

\section{METHODS}

This is a prospective observational study, conducted at the National Institute of Oncology (INO) in Rabat on 8 consecutive weekly digestive cancer MDTs between May 23, 2019 and July 18, 2019. All the cases discussed during these meetings were included in the study, without exclusion. This study received the agreement of the ethics committee of biomedical research of the Mohammed V University of Rabat (number 5/20) and was registered on clinicaltrial.gov under the number NCT04000802. The physicians participating in the MDTs were informed of the study before its beginning.

\section{CONTEXT}

The National Institute of Oncology in Rabat (INO) is a pioneering national and African center in the treatment of cancer. It is part of the university hospital center of Rabat, Morocco. It offers specialized tertiary services in addition to the regional healthcare network. It provides care for adult solid tumors. It is the only Moroccan public center which has a complete multidisciplinary technical platform including surgery, radiotherapybrachytherapy, medical oncology, radiology, pathological anatomy, genetics, psychology and dental care. He also provides pain management and palliative care. In 2019, INO recruited 6,302 new cases of cancer, of which 1,310 were digestive. A MDT dedicated to digestive cancers has been taking place regularly every week since 2010 , with the aim of presenting all patients suffering from digestive cancer. The hospital protocol specifies that a minimum quorum composed of a surgeon, a medical oncologist and a radiotherapist is required for each MDT. The main members of our digestive oncology RCP are surgeons, medical oncologists, radiotherapists, radiologists, gastroenterologists, pathologists and a geneticist. Since October 2018, a dedicated module has been added to the hospital information system and has made it possible to facilitate the sharing of information between the electronic medical record and the MDT decisions. In order to ensure the quality of the information for each presentation, recommendations were developed and shared with the hospital doctors specifying how to structure the comorbidities, clinical and para-clinical data and treatments received. The moderation of the meetings is ensured by the surgeons.

\section{MODe TOOL}

We used the "Metric for the Observation of Decision-making (MODe)" tool for the evaluation of RCP teams [5, 8, 14-18]. The tool is based on the 5-point Likert scale ranging from "high performance" (coded by 5) to "poor performance" (coded by 1 ). The MDT-MODe takes into account the following parameters (19): 1) the quality of the information presented on the patient, which includes six variables, namely the patient's history, radiological images, histopathology, psychosocial problems, co-morbidities and the quality of information on the patient's perspective and preferences. The sum of the scores of the six variables represents the overall quality of the information presented for a patient, the highest scores indicating better quality; 2) the quality of the contribution of the different specialists to the discussion, which includes six individual variables scored on a five-point scale, representing the contribution of the surgeons, oncologists, radiologists, pathologists, nurses and the meeting moderator. However, there was no involvement of nurses, so this variable was not analyzed. The sum of the scores of the six variables represents the overall quality of the team contribution; the highest scores indicate better quality; 3 ) the ability of the team to arrive at a recommendation for care for a patient which is a categorical variable (yes, no, reported).

\section{DATA COLLECTION}

An independent observer physician was responsible for collecting the data. She was trained to use the MDT-MODe tool in simulation on MDTs videos and then by attending a live MDT before the start of the study. The tool was used in its original version in English. Data collection was done on an electronic form (Google Form). 


\section{STATISTICS}

Quantitative values are presented as average (with standard deviation) or median (and quartiles), as appropriate. Qualitative data are presented in number and percentage. IBM SPSS Statistics version 23.0 was used for the statistical analyzes.

\section{RESULTS}

\section{Characteristics of the MDTs and participants:}

A total of 228 cases were evaluated during 8 consecutive weekly MDTs, including 67\% of the cases in the pre-therapeutic phase, $24 \%$ of the posttherapeutic phase, and $8 \%$ of the cases of surveillance or recurrent cancer cases. Four MDTs discussed more than 32 patients per meeting. The average duration of MDT was $90 \mathrm{~min}$ with an average of 2.55 minutes per patient (Table I)

Table I: Characteristics of SPC observed

\begin{tabular}{lccccc}
\hline & Median & Mean & Minimum & Maximum & Total \\
\hline Cases by MDT & 32 & 28.5 & 13 & 44 & 228 \\
Pre-treatment Phase & 21 & 19.25 & 7 & 31 & 154 \\
Post-treatment Phase & 6 & 6.85 & 1 & 14 & 55 \\
Monitoring or recurrence & 1 & 2.37 & 0 & 8 & 19 \\
Duration of MCT & $1 \mathrm{~h} 44 \mathrm{~min}$ & $1 \mathrm{~h} 30 \mathrm{~min}$ & $27 \mathrm{~min}$ & $2 \mathrm{~h} 07 \mathrm{~min}$ & - \\
Discussion time per case & $2 \mathrm{~min} 30 \mathrm{~s}$ & $2 \mathrm{~min} 55 \mathrm{~s}$ & $30 \mathrm{~s}$ & $10 \mathrm{~min} 16 \mathrm{~s}$ & - \\
Number of specialists per MDT & 9 & 9 & 5 & 12 & - \\
\hline
\end{tabular}

During the 8 MDTs, the team was composed of specialists in surgery, medical oncology, radiology, radiotherapy, gastroenterology, and oncogenetic as well as internal physicians and residents in these different disciplines. On average 9 specialists were present by MDT. It is noted that a pathologist was present at only one CPR.

\section{Quality of patient information}

As shown in Table 2, the disease history (mean = $4.25 ; \mathrm{SD}=1.11)$, radiological data $($ mean $=3.61 ; \mathrm{SD}$
$=1.40)$ and the comorbidities (mean = 3.12; standard deviation $=1.78$ ) were of good quality in the MDTs observed. In 150 (65.8\%), 101 (44.3\%) and $97(42.5 \%)$ cases, history, radiological information, and comorbidities, respectively, received a score of 5 .

Psychosocial information (mean $=1.29$; standard deviation $=0.94)$ and patient views $($ mean $=1.03$; standard deviation $=0.37$ ) had the lowest scores. In $206(90.4 \%)$ and $226(99.1 \%)$ cases, psychosocial information and patient perspectives, respectively, were scored 1 , indicating that no such information was received (Table II).

Table II: Descriptive statistics of the quality of information presented during MDTs

\begin{tabular}{lcccc}
\hline & Average & Standard deviation & Median & Min-Max \\
\hline History & 4.25 & 1.11 & 5 & $1-5$ \\
Radiology & 3.61 & 1.40 & 3 & $1-5$ \\
Pathology & 2.41 & 0.92 & 3 & $1-3$ \\
morbidities & Co-3.12 & 1.78 & 3 & $1-5$ \\
Psychosocial information & 1.29 & 0.94 & 1 & $1-5$ \\
Patient's point of view & 1.03 & 0.37 & 1 & $1-5$ \\
\hline
\end{tabular}




\section{Quality of the contribution of the various specialists to the discussion}

On average, the quality of the moderator's behavior was judged to be good (average $=4.32$; standard deviation $=0.94$ ). For quorum members, surgeons (mean $=4.56 ;$ standard deviation $=0.98)$ and oncologists $($ mean $=3.99 ;$ standard deviation $=1.57)$ obtained higher scores, compared to radiotherapists (mean $=1.74 ;$ standard deviation $=1.43)$. A disparity in the contribution of other specialists was noted. Radiologists contributed with a (mean $=2.36$; standard deviation $=1.81)$ and pathologists contributed with a (mean $=1.02$; standard deviation $=0.26)$. (Table III).

Table III: Descriptive statistics of the quality of contribution of specialists

\begin{tabular}{lllll}
\hline & Average & Standard deviation & Median & Min-Max \\
\hline Moderator & 4.32 & 0.94 & 5 & $3-5$ \\
Surgeons & 4.56 & 0.98 & 5 & $1-5$ \\
Oncologists & 3.99 & 1.57 & 5 & $1-5$ \\
Radiologists & 2.36 & 1.81 & 1 & $1-5$ \\
Radiotherapists & 1.74 & 1.43 & 1 & $1-5$ \\
Pathologists & 1.02 & 0.26 & 1 & $1-1$ \\
\hline
\end{tabular}

\section{Team capacity to reach a decision}

A treatment recommendation was made in $84.6 \%$ of the patients $(\mathrm{N}=193)$, while $9.2 \%(\mathrm{~N}=21)$ received a delayed decision due to lack of radiological or histopathological data or because other investigations were needed. For $6.1 \%$ of patients (N =14), no decision was made during the MDT.

\section{DISCUSSION}

The MDT-Mode tool allowed us to evaluate the decision-making process during the digestive cancer MDTs. It showed a disparity in the quality of the different aspects of the information presented as well as a great disparity between the specialists' participation.

Compared with other studies that have used the MDT-MODe, reported history and radiology data are usually of good quality. An observational study from Germany found that the history $($ mean $=4.9)$ and the radiological information $($ mean $=4.5$ ) were presented with high quality [20]. The same result is found in another study from the United Kingdom (history of the disease 3.91; radiological information 3.62) [5]. Our study joins the results of these studies showing a high performance in the presentation of history and radiological information. This may be due to the presence of clear and disseminated recommendations to all participating physicians about the clinical and paraclinical information to be included in each presentation.
Our study showed an average quality in comorbidities presentation during MDTs (average = 3.12] but it remains higher when compared with other studies. The average in the other studies varies between 1.36 and 2.83 [5, 20]. In the local MDT recommendations, each presentation must contain the American Score of Anesthesiologists score (ASA), performance status and nutritional grade scores to assess the patients. The standardization of the mode of presentation of comorbidities could explain the good score in this study.

Psychosocial information was most likely presented with low quality as psychosocial information is not mentioned in the local recommendations. Regarding the patient point of view, the results of most studies evaluating the quality of MDTs have shown that it is often or almost always absent $[5,10,11,15,18,21]$. In our study, it was discussed during the 8 MDTs only in two cases. For the rest, the decision was communicated to patients during a scheduled consultation after the MDT, and if the patient refuses treatment, the case was discussed again in a future MDT to reassess and reach a new adequate decision. Regarding the contribution of the team members, the surgeons obtained an average of 4.56 , followed by the meeting moderator (average of 4.32) and oncologists (average of 3.99). The high score of the surgeons' participation can be explained by the fact that most of the cases presented are from the surgical oncology department, and especially that the meeting moderator was always a surgeon, which 
must have certainly amplified the surgeons' score. Although a radiologist was present at all meetings, the radiologists obtained a lower score (average of 2.36). This is not necessarily due to a lack of participation by radiologists but rather to a lack of systematic presentation of radiological images. During the study period, there was a technical problem to access remote imaging exams. In addition, even when imagery was available, it was most often X-ray films, which is not optimal. The contribution of pathologists obtained a low average explained by their absence.

Our MDT almost exclusively discusses digestive cancer cases, where radiotherapy plays a key role in the management of cancers of the esophagus and rectum. Apart from these cases, radiotherapy is generally not indicated, and this explains the low score for the contribution of radiotherapists (1.74 on average). However, in the other studies the radiotherapists do not systematically participate in the MDTs. In addition, the inconsistent presence of pathologists at the RCP and the absence of an image digitization system integrated into the computerized management system of the laboratory explains the low score of the pathology information. This result was low compared to other studies [5, 15].

One of the main strengths of this study is that it is the first prospective study which has examined the decision-making processes during MDTs in Morocco using a validated tool which allows comparison with other international studies. It included 228 cases which allowed us a reliable analysis. It made it possible to identify precisely the strengths and the weaknesses of MDTs in our context.

Probably, the main weakness of the work is the Hawthorne effect [22]. MDTs members were informed that they were being assessed during these eight weeks, and as a result, this could have influenced their behavior and therefore biased the results. Second, in most studies there were two independent observers to limit the risk of bias. It would have been interesting to have a second observer to compare the results and study the agreement between them.

The purpose of this evaluation is to propose specific improvement measures, using the MDT-MODe tool. Following our results, our main recommendations are to strengthen the quorum by other specialists; especially radiologists because of their important role in discussion and decision-making in patients with digestive cancer. To allow a more effective presentation of radiological information and a clear contribution from radiologists, the implementation of a PACS (Picture Archiving and Communication System) and a double projection system would allow accessibility of images and observation simultaneously with all stakeholders and would facilitate decision-making. We also propose to make doctors aware of the importance of psychosocial information in the patient-centered therapeutic approach, and to integrate this point in the local MDT recommendations.

\section{CONCLUSIONS}

The use of the MODe tool made it possible to methodically identify the strengths and weaknesses of the decision-making mode during MDTs in our context. The main improvements proposed through this work are to widen the quorum to include radiologists, to facilitate access to and display of medical imagery and include psychosocial information and patient perspective. Regular and standardized evaluation would identify areas for development and continuous improvement.

\section{List of Abbreviations:}

MDT: Multidisciplinary team oncology meeting. MODE: Metric for the Observation of Decision-Making tool.

PACS: Picture Archiving and Communication System.

INO: National Institute of Oncology in Rabat

\section{REFERENCES}

1. Choudhury N, Hassen Y, Siddiqui J, Falzon A, Ghufoor K. A multidisciplinary audit of head and neck referrals: considerations for patients' timelines and outcomes. Eur Arch Otorhinolaryngol [Internet]. 2013 Nov;270(12):3121-6. Available from: http://dx.doi.org/10.1007/s00405-013-2453-9

2. Lamb BW, Brown KF, Nagpal K, Vincent C, Green JSA, Sevdalis N. Quality of care management decisions by multidisciplinary cancer teams: a systematic review. Ann Surg Oncol [Internet]. 2011 Aug;18(8):2116-25. Available from: http://dx.doi.org/10.1245/s10434-011-1675-6

3. Fleissig A, Jenkins V, Catt S, Fallowfield L. Multidisciplinary teams in cancer care: are they effective in the UK? Lancet Oncol [Internet]. 2006 Nov;7(11):935-43. Available from: https://linkinghub.elsevier.com/retrieve/pii/S147020 4506709408

4. Newman EA, Guest AB, Helvie MA, Roubidoux MA, Chang AE, Kleer CG, et al. Changes in surgical management resulting from case review at a breast cancer multidisciplinary tumor board. Cancer [Internet]. 2006 Nov 15;107(10):2346-51. Available from: http://dx.doi.org/10.1002/cncr.22266

5. Gandamihardja TAK, Soukup T, McInerney S, Green JSA, Sevdalis N. Analysing Breast Cancer Multidisciplinary Patient Management: A Prospective Observational Evaluation of Team Clinical Decision-Making. World J Surg [Internet]. 
2019 Feb;43(2):559-66. Available from: http://dx.doi.org/10.1007/s00268-018-4815-3

6. Taylor C, Atkins L, Richardson A, Tarrant R, Ramirez A-J. Measuring the quality of MDT working: an observational approach. BMC Cancer [Internet]. 2012 May 29;12:202. Available from: http://dx.doi.org/10.1186/1471-2407-12-202

7. Haward R, Amir Z, Borrill C, Dawson J, Scully J, West M, et al. Breast cancer teams: the impact of constitution, new cancer workload, and methods of operation on their effectiveness. $\mathrm{Br} \mathrm{J}$ Cancer [Internet]. 2003 Jul 7;89(1):15-22. Available from: http://dx.doi.org/10.1038/sj.bjc.6601073

8. Jalil R, Akhter W, Lamb BW, Taylor C, Harris J, Green JSA, et al. Validation of team performance assessment of multidisciplinary tumor boards. J Urol [Internet]. 2014 Sep;192(3):891-8. Available from: http://dx.doi.org/10.1016/j.juro.2014.03.002

9. Lamb B, Green JSA, Vincent C, Sevdalis N. Decision making in surgical oncology. Surg Oncol [Internet]. 2011 Sep;20(3):163-8. Available from: http://dx.doi.org/10.1016/j.suronc.2010.07.007

10. Lamb BW, Sevdalis N, Arora S, Pinto A, Vincent C, Green JSA. Teamwork and team decision-making at multidisciplinary cancer conferences: barriers, facilitators, and opportunities for improvement. World J Surg [Internet]. 2011 Sep;35(9):1970-6. Available from: http://dx.doi.org/10.1007/s00268011-1152-1

11. Jalil R, Ahmed M, Green JSA, Sevdalis N. Factors that can make an impact on decision-making and decision implementation in cancer multidisciplinary teams: an interview study of the provider perspective. Int J Surg [Internet]. 2013 Mar 14;11(5):389-94. Available http://dx.doi.org/10.1016/j.ijsu.2013.02.026

12. Lamb BW, Sevdalis N, Taylor C, Vincent C, Green JSA. Multidisciplinary team working across different tumour types: analysis of a national survey. Ann Oncol [Internet]. 2012 May;23(5):1293-300. Available from: http://dx.doi.org/10.1093/annonc/mdr453

13. Raine R, Xanthopoulou P, Wallace I, Nic A' Bháird C, Lanceley A, Clarke A, et al. Determinants of treatment plan implementation in multidisciplinary team meetings for patients with chronic diseases: a mixed-methods study. BMJ Qual Saf [Internet]. 2014 Oct;23(10):867-76. Available from: http://dx.doi.org/10.1136/bmjqs-2014-002818

14. Soukup T, Petrides KV, Lamb BW, Sarkar S, Arora $\mathrm{S}$, Shah $\mathrm{S}$, et al. The anatomy of clinical decisionmaking in multidisciplinary cancer meetings: A cross-sectional observational study of teams in a natural context. Medicine [Internet]. 2016 Jun;95(24):e3885. Available from: http://dx.doi.org/10.1097/MD.0000000000003885

15. Shah S, Arora S, Atkin G, Glynne-Jones R, Mathur $\mathrm{P}$, Darzi A, et al. Decision-making in Colorectal Cancer Tumor Board meetings: results of a prospective observational assessment. Surg Endosc [Internet]. 2014 Oct;28(10):2783-8. Available from: http://dx.doi.org/10.1007/s00464-014-3545-3

16. Lamb BW, Green JSA, Benn J, Brown KF, Vincent
CA, Sevdalis N. Improving decision making in multidisciplinary tumor boards: prospective longitudinal evaluation of a multicomponent intervention for 1,421 patients. J Am Coll Surg [Internet]. 2013 Sep;217(3):412-20. Available from: http://dx.doi.org/10.1016/j.jamcollsurg.2013.04.035

17. Lamb BW, Wong HWL, Vincent C, Green JSA, Sevdalis N. Teamwork and team performance in multidisciplinary cancer teams: development and evaluation of an observational assessment tool. BMJ Qual Saf [Internet]. 2011 Oct;20(10):849-56. Available http://dx.doi.org/10.1136/bmjqs.2010.048660

18. Lamb BW, Sevdalis N, Benn J, Vincent C, Green JSA. Multidisciplinary cancer team meeting structure and treatment decisions: a prospective correlational study. Ann Surg Oncol [Internet]. 2013 Mar;20(3):715-22. Available from: http://dx.doi.org/10.1245/s10434-012-2691-x

19. Lamb BW, Wong HWL, Vincent C, Green JSA, Sevdalis N. Teamwork and team performance in multidisciplinary cancer teams: development and evaluation of an observational assessment tool. BMJ Qual Saf [Internet]. 2011 Oct;20(10):849-56. Available http://dx.doi.org/10.1136/bmjqs.2010.048660

20. Hahlweg P, Didi S, Kriston L, Härter M, Nestoriuc Y, Scholl I. Process quality of decision-making in multidisciplinary cancer team meetings: a structured observational study. BMC Cancer [Internet]. 2017 Nov 17;17(1):772. Available from: http://dx.doi.org/10.1186/s12885-017-3768-5

21. Lamb BW, Sevdalis N, Mostafid H, Vincent C, Green JSA. Quality improvement in multidisciplinary cancer teams: an investigation of teamwork and clinical decision-making and crossvalidation of assessments. Ann Surg Oncol [Internet]. 2011 Dec;18(13):3535-43. Available from: http://dx.doi.org/10.1245/s10434-011-1773-5

22. Jawaid Shaw, Jasmohan S Bajaj. Is There Evidence of the "Hawthorne Effect" in Quality Improvement of Nutritional Consultation in Inpatients With Cirrhosis? Liver Transpl. 2020 May 7. doi: 10.1002/lt.25791. Online ahead of print. 